\title{
Sports Practice in Ordinary Environments and Social Integration of Young-Intellectual-Mild-Frailty Disabled Person
}

\author{
Jelleli Hilmi1, Hattabi Soukaina1, Ouelhazi Samira1, Ben Rejeb Riadh² \\ ${ }^{1}$ High Institute of Sports and Physical Education, Kef, Tunisia \\ ${ }^{2}$ Faculty of Human and Social Science of Tunis, Tunis, Tunisia \\ Email:h.jelleli@gmail.com
}

Received 31 March 2016; accepted 13 May 2016; published 16 May 2016

Copyright (C) 2016 by authors and Scientific Research Publishing Inc.

This work is licensed under the Creative Commons Attribution International License (CC BY). http://creativecommons.org/licenses/by/4.0/

(c) (i) Open Access

\begin{abstract}
The goal of this study is to show that the young intellectual disabled persons, enter easily in a social integration process when they practice a sport, better than when they do not practice. To evaluate this social integration, we adjust some elements that are essential or vital to this process. Three groups are formed. First, a group of non-sporting intellectual disabled persons, second a group of young intellectual disabled accompanied by young non-disabled sportsmen. From two questionnaires in Likert scale, five variables reflecting the essential elements of social integration are measured in pre-test and post-test on the three groups. We confirm that the autonomy, the pleasure of the effort, the competitiveness and the recognition are vital factors in social integration. Practicing sport is a strong support that helps young intellectual disabled in their social integration; thus it comprises the missing footbridge between institutional environment and the environment that are to integrate in.
\end{abstract}

\section{Keywords}

Sports Practice, Social Integration, Intellectual-Mild-Frailty Disabled Person

\section{Introduction}

The handicap scope tends to discard from a medical domain to that of social action. This stands as an object of a privileged study of human and social sciences. Durkheim (1986), Prahecq (1993), Clément (2000) and Gasparini

How to cite this paper: Hilmi, J., Soukaina, H., Samira, O., \& Riadh, B. R. (2016). Sports Practice in Ordinary Environments and Social Integration of Young-Intellectual-Mild-Frailty Disabled Person. Advances in Applied Sociology, 6, 217-223.

http://dx.doi.org/10.4236/aasoci.2016.65018 
(2005) assert the contribution of the physical and sports activity in the social standing. In the same line of idea Massion (2005) and Eberhard (1998) assert the integrative virtue of the physical and sports activities to the advantage of the handicapped person in the social standing. Hence; since the second half of twentieth century the interest in handicapped persons increased in Tunisia. Notably, the creation of associations like "Union Tunisien d'aide aux insuffisants Mentaux (1972)” and “Association des parents et Amis des handicaps en Tunisie (1981)”. This infatuation aims at helping the handicaped persons as well as their families which in itself draw a crucial support to their citizenship recognition. It is about to check to what extent a sport can contribute in social identification of mental handicapped category, in addition to their social integration.

\section{Methods}

\subsection{Population}

Thirty young volunteered participate in the study, as it's presented in the Table 1 . Ten non-sporting intellectual disabled persons are randomly selected from four Tunisian centers of aide to the handicapped persons, ten sporting non disabled persons are randomly selected from Tunisian athletic clubs and a group of intellectual disabled persons practicing a sport (10) ho constitute the population of the intellectual disabled persons practicing a sport in Tunisian ordinary clubs. Each group are composed of four girls and six boys each.

The twenty disabled persons participating in this study have the same level of mental frailty. They belong to the class "V" (intellectual disability) according to progressive color matrices (PM47, created by Raven in 1947) which was crossed by a clinical psychologist. The significant observed differences will not be due to a level of mildness but to the presence or not of sports practice.

\subsection{Protocol}

The study lasts four months (October 2014-January 2015) and two measurement scales are selected. Two intervention sessions are organized to obtain pre-test data and post-test data. Between these two sessions nothing is changed concerning the world of these youth. The choice is based on the integration elements: the recognition, the self esteem, and the autonomy. We withheld the goal importance scale (Lewthwaite, 1990). That we translated it especially to this study. The first goal importance factor labeled the Avoidance of Negative Social Evaluation comprised five items, the second goal importance factor, labeled Effort and Mastery, involved seven items. The third goal importance factor labeled Positive Experiences and Social Evaluation comprised seven items and the fourth goal importance factor was termed Competitiveness comprised five item. We also used the autonomy perception scale (Gillet et al, 2010). Responses to these items could range from 1 = "not important at all to me" to 7 = "very important to me" on a Likert scale.

\subsection{Statistical Analyses}

All statistical tests were processed using SPSS software for Windows (version 17.0, Chicago, USA). The normality of data sets was checked using the Kolmogrov-Smirnov test. Compound symmetry was tested using the Mauchlin test. to show that the young intellectual disabled persons, enter easily in a social integration process when they practice a sport, better than when they do not practice, a 2-way (3 groups: intellectual disabled non-practicing a sport, intellectual Disabled practicing a sport and Sporting non disabled X time of measurement: pre and post, as it's presented on the Table 2) analysis of variance with repeated-measures was used. When a difference was found, a Bonferroni post hoc test was applied. Statistical significance was set at $p<0.05$. All data are reported as mean \pm SD.

Table 1. Subjects.

\begin{tabular}{ccccc}
\hline & $\mathrm{N}$ & Age (years) & Height (cm) & $170 \pm 0.8$ \\
\hline Intellectual disabled non-practising a sport & 10 & $17.5 \pm 1.2$ & $73.8 \pm 6.2$ & $173 \pm 0.6$ \\
intellectual disabled practising a sport & 10 & $17.8 \pm 1.7$ & $173 \pm 0.5$ & $76.2 \pm 2.4$ \\
Sporting non disabled & 10 & $17.6 \pm 1.3$ & 1.8 \\
\hline
\end{tabular}


Table 2. Goals importance pre and post mean scores for the 3 groups $(n=30)$.

\begin{tabular}{ccccccccc}
\hline & \multicolumn{2}{c}{ ANSE } & \multicolumn{2}{c}{ EM } & \multicolumn{2}{c}{ PESE } & \multicolumn{2}{c}{ C } \\
\cline { 2 - 10 } & Pre-test & Post-test & Pre-test & Post-test & Pré-test & Post-test & Pre-test & Post-test \\
\hline IDNS & $21.80 \pm 3.08$ & $24.50 \pm 2.46$ & $26.20 \pm 1.69$ & $26.60 \pm 1.65$ & $26.80 \pm 2.57$ & $31.10 \pm 3.03$ & $17.800 \pm 2.44$ & $22.30 \pm 1.82$ \\
IDS & $23.90 \pm 1.52$ & $25.30 \pm 2.11$ & $27.60 \pm 3.86$ & $32.40 \pm 3.2^{\dagger}$ & $27.10 \pm 2.13$ & $37.80 \pm 2.04^{\dagger \S}$ & $18.500 \pm 4.24$ & $27.80 \pm 3.47^{\dagger}$ \\
SND & $26.300 \pm 4.27$ & $27.00 \pm 3.19$ & $28.90 \pm 2.5$ & $31.50 \pm 2.64^{\ddagger}$ & $27.40 \pm 2.55$ & $29.80 \pm 2.86^{\ddagger}$ & $24.60 \pm 4.41$ & $26.60 \pm 3.74^{\ddagger}$ \\
\hline
\end{tabular}

IDNS = Intellectual disabled non-practicing a sport. IDS = intellectual Disabled practicing a sport. SND = Sporting non disabled. ANSE = avoidance of nega-

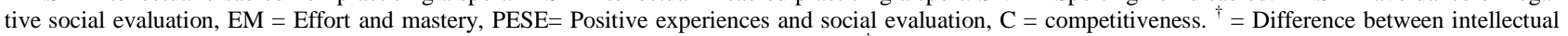
disabled non-practicing a sport and intellectual Disabled practicing a sport $(p<0.05) .{ }^{\ddagger}=$ difference between intellectual disabled non-practicing a sport and Sporting non disabled $(p<0.05){ }^{\S}=$ difference between intellectual Disabled practicing a sport and Sporting non disabled $(p<0.05)$.

\section{Results}

Concerning the sub-scale ANSE (Graphic 1), no significant effect of the time of measurement was observed $\left(\mathrm{F}_{1,54}=7.46 ; p=0.112\right)$, with no difference between the 3 groups $\left(\mathrm{F}_{1,54}=12.1 ; p=0.77\right)$ and no interaction between pre-to-post and condition $\left(\mathrm{F}_{1,54}=0.61 ; p=0.55\right)$. Concerning the sub-scale $\mathrm{EM}$, no significant effect of the time of measurement was observed $\left(\mathrm{F}_{1,54}=4.19 ; p=0.17\right)$, with no difference between the 3 groups $\left(\mathrm{F}_{1,54}=\right.$ 3.78 ; $p=0.21$ ) with an interaction between pre-to-post and condition $\left(\mathrm{F}_{1,54}=3.29 ; p=0.45\right)$ (Graphic 2$)$. Bonferroni post hoc test allow to show that non-sporting intellectual disabled have significantly less desire to the effort compared to the disabled sportsmen (26.6 VS 32.4; $p<0.01$ ) and less than the non-disabled sportsmen (26.6 VS 31.5; $p<0.01$ ). Bonferroni post hoc test allow to show that no significant difference between the disabled sportsmen and the non-disabled sportsmen (32.4 VS 31.5; $p=0.82$ ). Concerning the sub-scale PESE, no significant effect of the time of measurement was observed $\left(\mathrm{F}_{1,54}=5.33 ; p=0.15\right)$, with no difference between the 3 groups $\left(\mathrm{F}_{1,54}=0.96 ; p=0.51\right)$ with an interaction between pre-to-post and condition $\left(\mathrm{F}_{1,54}=14.46 ; p<0.00\right)$ (Graphic 3). Bonferroni post hoc test permit to show that the non-sporting intellectual disabled are less searching social recognition in comparison to sporting disabled: (31.1 VS 37.8; $p<0.000$ ). Moreover, sporting disabled are searching more social recognition better than non-disabled sportsmen (37.8 VS 29.8; $p<0.000$ ). Speaking of the sub-scale "Competitiveness", an significant effect of the time of measurement was observed $\left(\mathrm{F}_{1,54}=6.05 ; p=0.13\right)$, with a difference between the 3 groups $\left(\mathrm{F}_{1,54}=2.24 ; p=0.31\right)$ with an interaction between pre-to-post and condition $\left(\mathrm{F}_{1,54}=7.96 ; p=0.01\right)$ (Graphic 4). Bonferroni post hoc test allow to demonstrate that the non-sporting intellectual disabled are searching less competitiveness compared with sporting disabled (22.3 VS 27.8; $p=0.002$ ) and to the sporting non disabled (22.3 VS 26.6; $p=0.011$ ). An ANOVA was realized with the autonomy score on the three groups as a dependent variable and the test (pre-test, post-test) as a factor of repeated measurements (Graphic 5). No significant effect of the time of measurement was observed $\left(\mathrm{F}_{1,54}=1.26 ; p=0.38\right)$, with no difference between the 3 groups $\left(\mathrm{F}_{1,54}=5.79 ; p=0.15\right)$ with an interaction between pre-to-post and condition $\left(\mathrm{F}_{1,54}=11.16 ; p<0.00\right)$. Bonferroni post hoc test allowed to demonstrate that non-sporting intellectual disabled seem less autonomous compared to sporting disabled (56.9 VS 64.05; $p<0.00$ ) and in comparison with non disabled that are practicing sport (56.9 VS 68.6; $p<0.00$ ). Furthermore, Bonferroni post hoc test, allowed to show that autonomy scores during pre-test were significantly different amongst sporting intellectual disabled and the sporting non disabled (49.8 VS 67.8;), and that, this difference disappears in the post-test (64.05 VS 68.6; $p=0.68)$.

\section{Discussion}

In this study we searched to evaluate social integration of young intellectual sporting disabled persons in comparison to young non-sporting disabled persons, in addition to a group of non-disabled sportsmen. This evaluation stands on the elements that are essential for the integration: the autonomy, the self-image and that of others, social recognition, the overrun of the self and the competitiveness (Lawthwaite, 1990). Results did not put in evidence the positive impact of sports practice on the self-image of intellectual disabled persons. Hence, an intervention nearby young intellectual disabled to promote their social integration which should not targeting the increase of the self-image. Fischer (1991) relying on Goffman works indicates that the individual can control the image that he provides on himself by presenting it in a way seems to that people accept. The control performance 


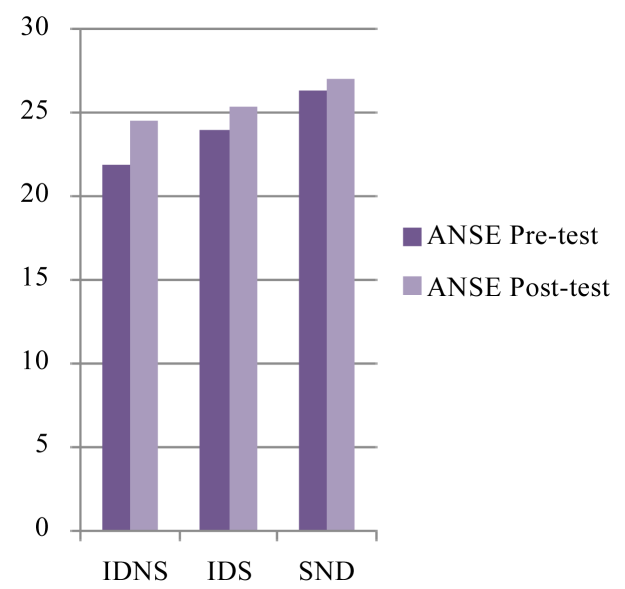

Graphic 1. Pre-test and post-test average of the subscale ANSE.

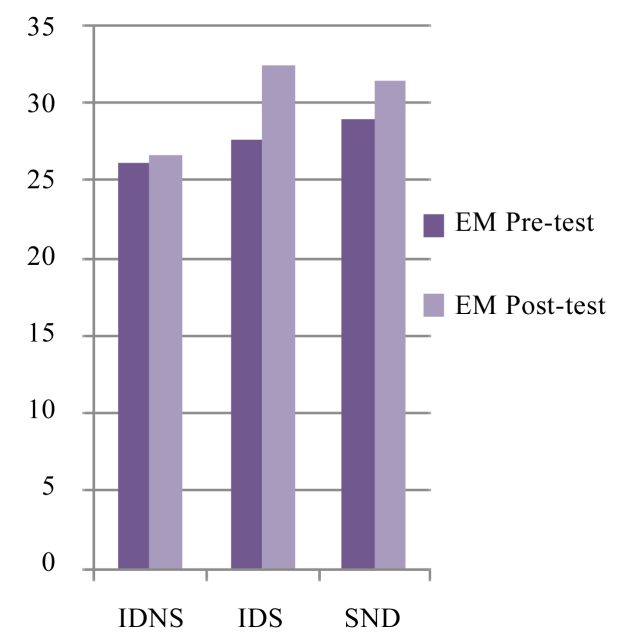

Graphic 2. Pre-test and post-test average of the subscale EM.

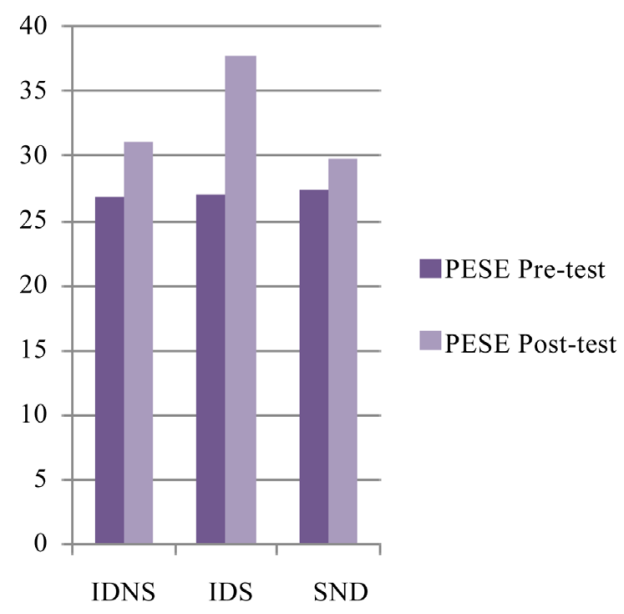

Graphic 3. Pre-test and post-test average of the subscale PESE. 


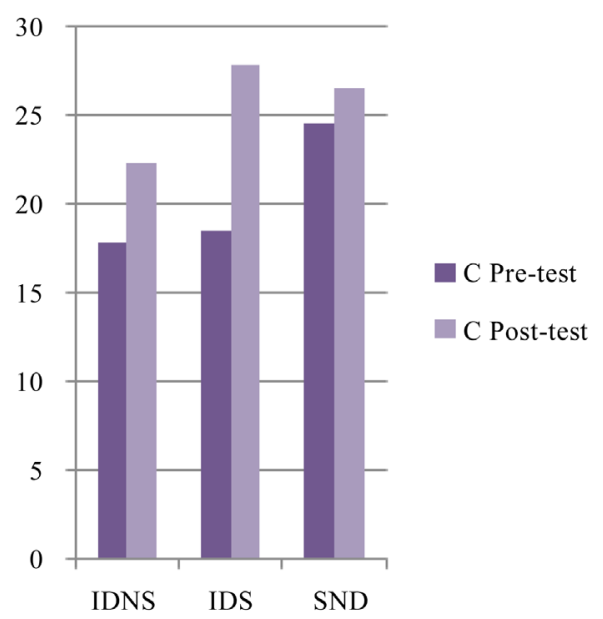

Graphic 4. Pre-test and post-test average of the subscale C.

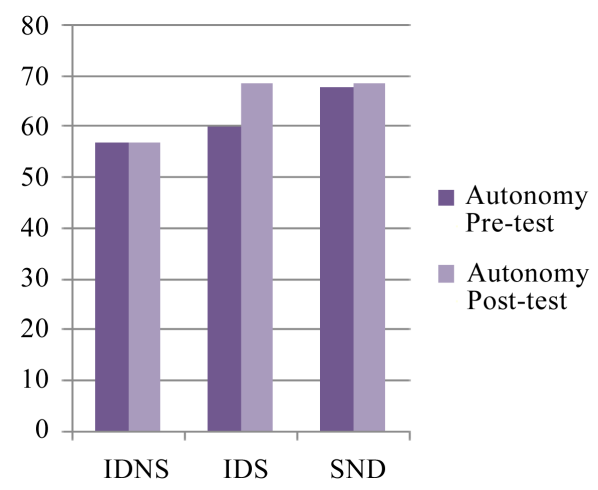

Graphic 5. Pre-test and post-test average of the Autonomy.

notion that is developed by the author reveals that all importance of actor game can be passed back acceptable in the eyes of others and consequently has an impact on them. Confronted with society by sports practice, intellectual disabled face their image for not appearing marginal in the environment that they should integrate in. This adaptation capacity is found among all intellectual disabled, but they exploit it only when found in situations that demand that. This is why confronting this young disabled to new and important situations stimulate their adaptation capacity and the necessary identification process of socialization. A regular contact with the environment where they face the act to integrate should help this stimulation.

Also, results show that young intellectual disabled show a clear desire towards the effort and the mastery of it when they practice a sport better than when they practice none. Therefore, this difference does not appear among sporting young disabled and among the non-sporting disabled. In an institution like Handicapped help centers, sport is not subject to a rating or a classification. As a result youth do not have a direct feedback on the game and so they are not aware of their evaluation; is it positive or negative. Whereas in a competition framework or when a classification is established, youth directly know their evolution, compared to others that are existing in each competition. So that it is not surprising to observe significant differences between "non-sporting" disabled group and "sporting" disabled group as well as between "non-sporting” group of disabled and "sporting" group of non-disabled. There is no significant difference in observed between sporting disabled persons among ordinary clubs and sportsmen that are non disabled. We deduce that intellectual disabled have adapted to the ordinary sporting environment while developing their spirit equally to that of "non-sporting disabled persons".

Results make clear that young sporting disabled persons attribute further towards social recognition better than non-sporting disabled as well as non-disabled sportsmen. The young non-sporting disabled subscribed in 
help centers of handicapped persons and made back and forth movements: house-center, center-house, two places where they feel that are familiar and recognized. As a result, they are rarely in contact with the environment that are to integrate in which is simply society. They are recognized within their receptive families as member of it. So, they do not need to prove to others and to oneself the membership to this group-family. To be positioned or placed in help centers promotes the feeling of that they are recognized by others as have on education concerning special needs. Also they look to this placement as a failure. They know appreciating this recognition before ignoring the existence problem. Dostoïevski notices that the individual is ready to accept the most humiliating situations as help him declare his existence and that the most insulting remarks are better than recognition absence (cited by Todorov, 2004).

As for intellectual disabled that are practicing a sport among ordinary clubs, they become active members within Tunisian teams and they participate in competitions in ordinary environments. They look for to be recognized sportsmen or simply famous. Showing their proof at adapted and classical meetings allow them to erase the label "intellectual disabled" subscribed on them since diagnosis. The great importance of a help center that it allows young disabled to do a sport of competition among others and then compete against them. All this help them proof to oneself and to others that they are also capable of doing exactly like those that are non-disabled persons.

Results allowed showing that the competitiveness spirit is more important among "sportsmen" more than among "non-sportsmen". It could be obvious but it is not sufficient to be sportsmen to love winning. The Lawthwaite (1990) formulated items are focusing on the rivalry between individuals, on the importance of winning in games as well as an importance of not making errors. We could find this out of sports framework like games found in neighborhood. We obtain significant differences between these three groups; "non-sporting” disabled are less competitive compared to "sporting" disabled that are belonging to ordinary clubs and less than non disabled sportsmen. More than that, there is no observed significant difference between the group of disabled and that of non disabled. Sporting disabled show then a competitive spirit equal to that of non-disabled sportsmen and significantly superior to that of "non-sporting” disabled. Reminding that competition spirit designs the envy or the desire to de well and to progress in his practice. To have the desire to do well, to succeed, making the less possible errors, show a clear concentration capacity on the task, but an equally commitment to his practice motivated by confidence which is accorded to his progression capacity. Works on this theme do not precise certain aspects of intellectual disability such as the timidity or the lack of confidence, but discussing with persons that have a daily contact with these youth, proves that these aspects are recurring. Educators talk about great emotionality, a timidity (fear of the lack of vocabulary during a conversation) fear of a constant failure, it is about behaviors that are often observed by different teachers in centers that help persons suffering from mental disability which is not over generalized among all intellectual disabled. Can a sporting activity help fighting these behaviors? We can equally think that these behaviors are less pronounced amongst young intellectual disabled that have a desire to practice a sport in an ordinary environment.

Finally, results concerning the autonomy variable prompt us to discuss them. In effect, the group of "non sporting persons" disabled differs from that of sporting intellectual disabled persons and compared to that of non-disabled sportsmen. This indicates that "sporting” disabled and non disabled sportsmen feel more autonomous in comparison to no-sporting disabled. The post-hoc analysis reveals a significant difference between the pre-test and the post-test. To be more interested, be closer to each group, we observe that there is a significant difference at the level of pre-test between the group of sporting disabled and sporting non disabled group (49.8 VS 67.8). By instance, this difference will be not found in post-test (64.05 VS 68.6). Moreover, the noticed analysis on group of sporting disabled persons reveals a significant increase. So we can conclude that young sporting disabled persons feel more autonomous at the post-test in comparison with pre-test. This difference is not found among non-disabled sportsmen nor among non sporting disabled. Thus we can affirm that the cause of autonomy perception gain amongst young intellectual disabled in the ordinary clubs accompaniment. If we will favorite social integration of young intellectual disabled with mild frailty the intervention will be axed on the autonomy perception that lead us to conclude that practicing a sport is a great support to increase autonomy perception.

So, sport can be recognized as a socialization agent. Autonomy gains makes stronger, the responsibilities. That grants us to favorite social recognition because it confirms our social participation within this environment. Increasing its autonomy perception could be the departure point of numerous evolutions that lead to social integration of young intellectual disabled persons that have a mild frailty. 


\section{References}

Clément, M. (2000). Sport and Insertion. Voiron: PUS

Durkheim, E. (1986). The Moral Education. Paris: PUF.

Eberhard, Y. (1998). Better Know the People with Mental Disabilities. EPS, n² 2699, 67-69

Fischer, G.-N. (1991). The Domains of the Social Psychology, the Volume 2, the Processes of the Social. Paris: Bo-Pré.

Gasparini, W. (2005). The Contradictions of the Integration by the Sport. Integration by the Sport (pp. 243-260). Supervised by Falcoz, M., \& Koebel, M. Paris: l’Harmattan.

Gillet, N., Vallerand, R.-J., Paty, E., Gobancé, L., \& Berjot, S. (2010). French Validation and Adaptation of the Perceived Autonomy Support Scale for Exercise Settings to the Sport Context. International Journal of Sport and exercise Psychology, 8, 117 http://dx.doi.org/10.1080/1612197X.2010.9671937

Lewthwaite, R. (1990). Threat Perception in Competitive Trait Anxiety: The Endangerment of Important Goals. Journal of Sport and Exercise Psychology, 12, 280-300.

Massion, J. (2005). Sport and Autism. Le bulletin scientifique de l’arapi n¹6.

Prahecq, H. (1993). Organized Sports Activities and Variation of the Self-Esteem at the Teenagers. In Sport, Social Relationships and Collective Action. Proceedings of the colloquy 14 et 15 october 1993, Bordeaux.

Todorov, T. (2002). Under the Other People's Gaze. The I, of the Normal for the Pathological. Coordonné par Chapelle, G. (2004) 131, 87-96, Paris: Human Sciences. 